\title{
Simultaneous determination of four active pharmaceuticals in tablet dosage form by reversed-phase high performance liquid chromatography
}

\author{
Madhusudan T Bachute ${ }^{1 *}$, Sunil V Shanbhag ${ }^{2}$, Shankar L Turwale ${ }^{3}$ \\ ${ }^{1}$ Department of Chemistry, KBP College, Pandharpur, Solapur University, Solapur, MS, 413304, ${ }^{2}$ Department of Chemistry, $R$ \& \\ $D$ Centre, Bharathiar University, Coimbatore, TN 641046, ${ }^{3}$ Department of Chemistry, KBP College, Pandharpur, Solapur \\ University, Solapur, MS 413304, India
}

*For correspondence: Email: mbachute@gmail.com; Tel: +918888531274

Sent for review: 19 December 2018

Revised accepted: 17 September 2019

\begin{abstract}
Purpose: To develop a single, low-cost and rapid analytical method for the simultaneous determination of four active components - chlorpheniramine maleate, paracetamol, phenylephrine hydrochloride and caffeine - in a tablet dosage form.

Method: This method was based on reverse-phase high performance liquid chromatography (RPHPLC) and involved the use of a C-18 column (250 x $4.6 \mathrm{~mm}, 5.0 \mu \mathrm{m})$, a mobile phase consisting of buffer solution and methanol at a flow rate of $1.00 \mathrm{~mL} / \mathrm{min}$, and gradient determination with UV detection at $220 \mathrm{~nm}$.

Results: Retention time was 4.33, 10.36, 13.85, and $17.35 \mathrm{~min}$ for phenylephrine hydrochloride, paracetamol, caffeine, and chlorpheniramine maleate, respectively. Specificity data showed no interference from the excipients, and accuracy of the method was close to $100 \%$. The method was validated as per the guidelines of International Council for Harmonisation of Technical Requirements for Pharmaceuticals for Human Use (ICH), and all the results met the acceptance criteria for accuracy, precision, linearity, specificity, limit of quantitation, limit of detection, and robustness.

Conclusion: This method can successfully perform quantitative assessment of phenylephrine $\mathrm{HCl}$, chlorpheniramine maleate, paracetamol, and caffeine in tablet combination dosage forms faster and more cost-effectively than conventional methods.
\end{abstract}

Keywords: Caffeine, Chlorpheniramine, Paracetamol, Phenylephrine, RP-HPLC, Tablets, Simultaneous quantitation, Combination dosage

\footnotetext{
This is an Open Access article that uses a fund-ing model which does not charge readers or their institutions for access and distributed under the terms of the Creative Commons Attribution License (http://creativecommons.org/licenses/by/4.0) and the Budapest Open Access Initiative (http://www.budapestopenaccessinitiative.org/read), which permit unrestricted use, distribution, and reproduction in any medium, provided the original work is properly credited.

Tropical Journal of Pharmaceutical Research is indexed by Science Citation Index (SciSearch), Scopus, International Pharmaceutical Abstract, Chemical Abstracts, Embase, Index Copernicus, EBSCO, African Index Medicus, JournalSeek, Journal Citation Reports/Science Edition, Directory of Open Access Journals (DOAJ), African Journal Online, Bioline International, Open-J-Gate and Pharmacy Abstracts
}

\section{INTRODUCTION}

Pharmaceutical companies are increasingly pursuing combination dosage forms that can treat multiple symptoms simultaneously. A widely-used combination dosage form for the treatment of upper respiratory infections is the combination of phenylephrine hydrochloride, chlorpheniramine maleate, paracetamol, and caffeine, which is utilized for its analgesic, antipyretic, antihistamine, and antitussive activity. 
Chlorpheniramine maleate (CPM; 2-[p-chloro-[2dimethylamino) ethyl] benzyl] pyridine maleate) is used as an antihistaminic agent in allergic reactions. Paracetamol (PARA; N-[4hydroxyphenyl] acetamide) is a centrally- and peripherally-acting non-opioid analgesic and antipyretic. Phenylephrine hydrochloride (PHE; 3-[1-hydroxy-2-(methyl amino) ethyl] phenol hydrochloride) acts as nasal and sinus decongestant. Caffeine (CAF; 1,3,7-trimethyl-3,7dihydro-1 $\mathrm{H}$-purine-2,6-dione) is an addictive stimulant that elevates heart rate and respiration, confers psychotropic properties, and acts as a mild diuretic.

Various analytical methods, including spectroscopy [1] and high performance liquid chromatography (HPLC) [2-3], have been utilized for the estimation of CPM alone [1-3] in various dosage forms. Similarly, diverse analytical methods are available for the determination of PARA [4-7], PHE [8-11], and CAF [12-15] from different dosage forms. However, no single method is available for the simultaneous determination of all four active components in a combination form.

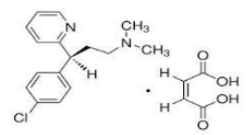

Chlorpheniramine maleate (CPM)

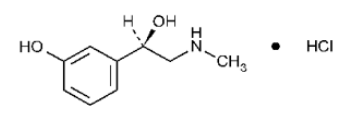

Phenylephrine HCL (PHE)

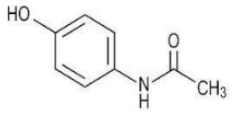

Paracetamol (PARA)

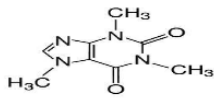

Caffeine (CAF)
Figure 1: Chemical structure of active ingredients determined from novel reverse-phase high performance liquid chromatography (RP-HPLC) characterization of a combination dosage form.

A survey of existing literature survey suggested that a single procedure capable of simultaneously determining multiple active components present in commercial drug dosage forms would be a useful alternative to existing methods, reducing both time and costs spent on individual, serialized determinations of combination drug forms.

\section{EXPERIMENTAL}

\section{Apparatus}

Prior to this study, we optimized our protocol using different ratios of methanol, water, and ammonium buffer solution. Our apparatus consisted of Dionex Gradient System with UV
Detector 730D and pump SP930 D. (ThermoFischerScientific, USA). Chromatographic separation was carried out at room temperature with a Cosmosil C-18 column $(250 \times 4.6 \mathrm{~mm}, 5.0 \mu \mathrm{m})$. (Nacalai Tesque ,Japan). Instrumental settings included a flow rate of $1.00 \mathrm{~mL} / \mathrm{min}$, column temperature of $30^{\circ} \mathrm{C}$, and detector wavelength of $220 \mathrm{~nm}$.

\section{Chemicals and reagents}

PHE, CPM, PARA, and CAF were supplied from Wallace Pharmaceuticals, Goa, India; HPLCgrade methanol, sodium dihydrogen phosphate dihydrate, and analytical research-grade tetra butyl ammonium hydrogen sulfate were from Merck, Mumbai, India. The water used was deionized and double-distilled. Tablets containing PHE, CPM, PARA, and CAF were obtained commercially (Helpex Anticold tablets). ( Sava Healthcare ,India ). Each tablet contained $10 \mathrm{mg}$ PHE, $2 \mathrm{mg}$ CPM, $500 \mathrm{mg}$ PARA, and $30 \mathrm{mg}$ CAF.

\section{Mobile phase}

\section{Mobile phase A:}

For mobile phase $\mathrm{A}, 1.56 \mathrm{~g}$ sodium dihydrogen phosphate dihydrate and $1.70 \mathrm{~g}$ tetra butyl ammonium hydrogen sulfate were transferred to a 1,000-mL volumetric flask and dissolved in water to reach a volume of $1,000 \mathrm{~mL}$, then mixed. The solution was then filtered through a $0.45-\mu \mathrm{m}$ filter and degassed.

\section{Mobile phase B: Methanol}

Table 1: Gradient profile of Mobile Phase A and B

\begin{tabular}{lcc}
\hline $\begin{array}{l}\text { Time } \\
(\mathbf{m i n})\end{array}$ & $\begin{array}{c}\text { Mobile phase A } \\
(\% \mathbf{v} / \mathbf{v})\end{array}$ & $\begin{array}{c}\text { Mobile phase B } \\
(\% \mathbf{v} / \mathbf{v})\end{array}$ \\
\hline 0 & 95 & 5 \\
18 & 55 & 45 \\
23 & 55 & 45 \\
25 & 95 & 5 \\
30 & 95 & 5 \\
\hline
\end{tabular}

\section{Preparation of solutions}

A working standard solution containing $10 \mu \mathrm{g} / \mathrm{mL}$ PHE, $2 \mu \mathrm{g} / \mathrm{mL}$ CPM, $500 \mu \mathrm{g} / \mathrm{mL}$ PARA, and 30 $\mu \mathrm{g} / \mathrm{mL}$ CAF was prepared by dissolving PHE, CPM, PARA, and CAF standards in $1 \mathrm{~L} 50 \%$ methanol. The mixture was sonicated for $30 \mathrm{~min}$ or until the standard dissolved completely. Sample solutions were prepared by finely powdering and weighing 20 tablets of the retail combination dosage. An amount of powder containing $10 \mathrm{mg}$ PHE, $2 \mathrm{mg}$ CPM, $500 \mathrm{mg}$ PARA, and $30 \mathrm{mg}$ CAF was added to a $100-\mathrm{mL}$ 
volumetric flask and diluted with $70 \mathrm{~mL} 50 \%$ methanol diluent, mixed well and sonicated for $30 \mathrm{~min}$, cooled to room temperature, and made up to the mark with additional diluent. A 2.5-mL aliquot of this solution was added to a $25-\mathrm{mL}$ volumetric flask and made up to the mark with additional diluent.

\section{RESULTS}

The HPLC procedure was optimized by developing a simultaneous assay method for PHE, CPM, PARA, and CAF. At a flow rate 1.00 $\mathrm{mL} / \mathrm{min}$, the gradient method of sodium dihydrogen phosphate dihydrate and tetra butyl ammonium hydrogen sulfate buffer solution with methanol gave acceptable retention time, number of theoretical plates, and good resolution for PHE, CPM, PARA, and CAF standards (Figure 2). The system suitability tests revealed that numbers of theoretical plates were above 2,000 and the tailing factor was less than 2 .

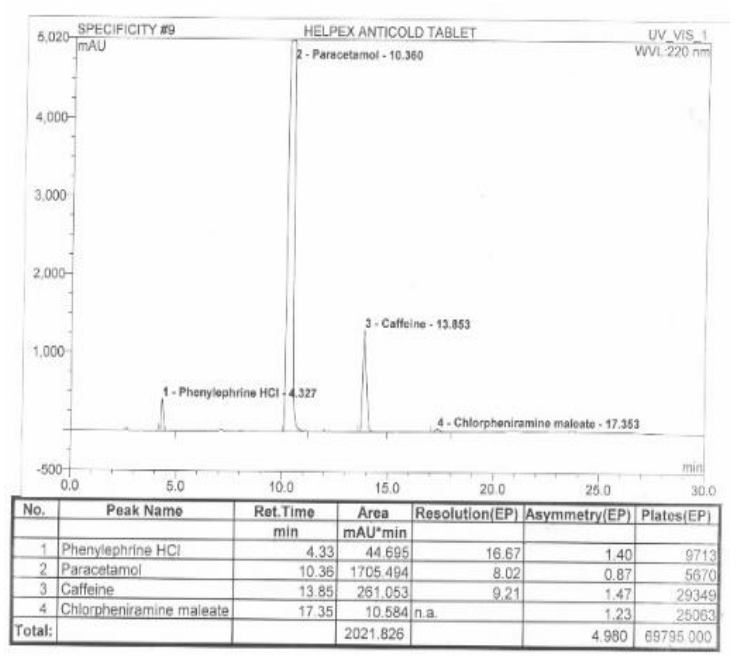

Figure 2: HPLC chromatogram of phenylephrine hydrochloride (PHE), chlorpheniramine maleate (CPM), paracetamol (PARA), and caffeine (CAF) standards

\section{Method development and validation parameters}

The reverse-phase HPLC (RP-HPLC) method was developed for simultaneous estimation of PHE, PARA, CAF and CPM in tablet dosage forms, with RTs of 4.33, 10.36, 13.85, and 17.35 min, respectively. All validation parameters were quantified as detailed below.

\section{Linearity}

Linearity was assessed by injecting five different concentrations of each standard in the mobile phase in triplicate into the chromatographic system, keeping the injection volume constant. The peak values of area were plotted against the corresponding concentrations to obtain the calibration graphs.

The linearity ranges for PHE, CPM, PARA, and CAF were $10-50 \mu \mathrm{g} / \mathrm{mL}, 2-10 \mu \mathrm{g} / \mathrm{mL}, 500-2,500$ $\mu \mathrm{g} / \mathrm{mL}$, and $30-150 \mu \mathrm{g} / \mathrm{mL}$, respectively. The slopes and their correlations with PHE, CPM, PARA, and CAF are shown in Table 2. PHE, CPM, PARA, and CAF showed a linear response between $10-50 \mu \mathrm{g} / \mathrm{mL}, 2-10 \mu \mathrm{g} / \mathrm{mL}, 500-2,500$ $\mu \mathrm{g} / \mathrm{mL}$, and $30-150 \mu \mathrm{g} / \mathrm{mL}$.

Table 2: Linearity slopes and correlation coefficients for PHE, CPM, PARA, and CAF

\begin{tabular}{lcc}
\hline Name of drug & Slope & Correlation \\
\hline & & coefficient \\
\hline Phenylephrine HCl & 1.001 & 0.999 \\
CP maleate & 1.019 & 1.000 \\
Paracetamol & 1.018 & 0.999 \\
Caffeine & 0.990 & 1.000 \\
\hline
\end{tabular}

\section{Precision}

Precision parameters assessed the repeatability of measurement and were calculated by injecting each standard solution six times, then measuring the peak areas. The RSD were 0.0861, 0.1093, 0.0330 and 0.2621 for PHE, CPM, PARA, and CAF respectively (Table 3 ).

\section{Limit of detection and limit of quantitation}

The limit of quantification (LOQ) and limit of detection (LOD) were evaluated based on signalto-noise ratios by serial dilution of PHE, CPM, PARA, and CAF solutions. The LOD and LOQ values are tabulated in Table 4.

\section{Robustness}

The robustness of the developed RP-HPLC method was assessed by making small, deliberate variations in the optimized method parameters and monitoring flow rate. The method was found to be unaffected when flow rate was changed $\pm 0.1 \mathrm{~mL} / \mathrm{min}$ (Table 5).

\section{Specificity}

The specificity of this method was assessed by examining the chromatogram and identifying where complete separation of PARA, PHE, CAF and CPM occurred. We observed no potential interference from the presence of excipients. The chromatographic peaks obtained were wellseparated at the baseline and were sharp in nature. 
Table 3: Inter- and intra-day precision studies for PHE, CPM, PARA, and CAF

\begin{tabular}{lcccc}
\hline Parameter & PHE & CPM & PARA & CAF \\
\hline Inter-day & & & & \\
\hline Peak mean area $(\mu \mathrm{g} / \mathrm{mL})$ & 51.1551 & 11.4132 & 58.3147 & 6.6934 \\
SD & 0.0441 & 0.0125 & 0.0193 & 0.0175 \\
RSD $(\%)$ & 0.0861 & 0.1093 & 0.0330 & 0.2621 \\
\hline Intra-day & & & & \\
\hline Peak mean area $(\mu \mathrm{g} / \mathrm{mL})$ & 51.1317 & 11.4153 & 58.3147 & 6.6934 \\
SD & 0.0396 & 0.0138 & 0.0193 & 0.0175 \\
RSD (\%) & 0.0775 & 0.1207 & 0.0330 & 0.2621 \\
\hline
\end{tabular}

SD: standard deviation; $R S D$ : relative standard deviation

Table 4: LOD and LOQ of PHE, CPM, PARA, and CAF

\begin{tabular}{lcccc}
\hline Parameter & PHE & CPM & PARA & CAF \\
\hline LOD $(\mu \mathrm{g} / \mathrm{mL})$ & 3.89 & 1.29 & 317.15 & 14.51 \\
LOQ $(\mu \mathrm{g} / \mathrm{mL})$ & 11.80 & 3.88 & 961.08 & 43.98 \\
\hline
\end{tabular}

Table 5: Robustness study for PHE, CPM, PARA, and CAF

\begin{tabular}{lccccc}
\hline Factor & Level & PHE & PARA & CAF & CPM \\
\hline Flow rate $(\mathbf{m L} / \mathbf{m i n})$ & & RT $(\mathbf{m i n})$ & RT $(\mathbf{m i n})$ & RT $(\mathbf{m i n})$ & RT $(\mathbf{m i n})$ \\
\hline 0.9 & -0.1 & 4.45 & 10.50 & 13.91 & 17.52 \\
1.0 & 0 & 4.33 & 10.36 & 13.85 & 17.35 \\
1.1 & +0.1 & 4.12 & 10.09 & 13.62 & 17.24 \\
\hline
\end{tabular}

Table 6: Recovery data for PHE, CPM, PARA, and CAF (mean, $n=6$ )

\begin{tabular}{lcccc}
\hline Recovery level (\%) & Name of drug & Recovery (\%) & SD & RSD (\%) \\
\hline 70 & & & & \\
\hline 100 & PHE & 100.43 & 0.02 & 0.07 \\
130 & & 98.50 & 0.04 & 0.08 \\
\hline 70 & & 100.61 & 0.05 & 0.09 \\
100 & CPM & 99.29 & 0.01 & 0.08 \\
130 & & 101.3 & 0.02 & 0.16 \\
\hline 70 & & 98.61 & 0.02 & 0.17 \\
100 & PARA & 100.86 & 0.04 & 0.09 \\
130 & & 99.30 & 0.20 & 0.33 \\
70 & & 99.61 & 0.16 & 0.20 \\
100 & CAF & 99.43 & 0.02 & 0.44 \\
130 & & 99.50 & 0.03 & 0.52 \\
\hline
\end{tabular}

Mean of six determinations

\section{Recovery}

Recoveries of PHE, CPM, PARA, and CAF from tablet samples ranged from 98.5-101.3\% (Table $6)$.

\section{Application of developed method to a commercial tablet formulation}

The developed RP-HPLC method identified similar quantities of PHE, CPM, PARA, and CAF in tablets as that listed on the product's label, ranging from $98.84-100.90 \%$ of the label amounts (Table 7). These findings confirmed our specificity results, indicating that excipients did not result in interference.

Table 7: Content of PHE, CPM, PARA and CAF in tablet formulation by HPLC technique

\begin{tabular}{lccc}
\hline Drug & $\begin{array}{c}\text { Label } \\
\text { claim }(\mathbf{m g})\end{array}$ & $\begin{array}{c}\text { Content } \\
\text { found }(\%)\end{array}$ & $\begin{array}{c}\text { RSD } \\
(\%)\end{array}$ \\
\hline PHE & 10 & 98.84 & 0.04 \\
CPM & 2 & 100.90 & 0.27 \\
PARA & 500 & 99.21 & 0.01 \\
CAF & 30 & 99.39 & 0.45 \\
\hline
\end{tabular}




\section{DISCUSSION}

Here, we describe a RP-HPLC method developed and validated for the simultaneous determination of PHE, CPM, PARA, and CAF in tablet combination dosage form. The total run time required for the method was less than 20 min for eluting all four active drugs (PHE, CPM, $P A R A$, and CAF), a dramatic reduction in run time per sample. Recovery of PHE, CPM, PARA, and CAF ranged from 98.84-100.90\% of reported label contents, and the slope and correlation coefficient nearly equaled one, indicating the high accuracy of this method. These results indicate that this method can be used for the routine analysis of combinations of four active pharmaceuticals, such as PHE, CPM, PARA and CAF, in tablet dosage form.

This method produced well-differentiated determinations, with resolutions consistently greater than 2. The mean peak area of the chromatograms was plotted against the concentration of PHE, CPM, PARA, and CAF to obtain the calibration curve. Repeatability and intermediate precision values were within the acceptable limits set by $\mathrm{ICH}$, indicating that the method is precise. Specificity experiments indicated no interference; the peaks of excipients and diluents did not overlap with the main peaks of PHE, CPM, PARA, and CAF. The LOD and $L O Q$ values obtained by the proposed method were low, which indicated the sensitivity of the method. The stability studies indicate that both standard and sample drugs were stable up to 24 $h$, and change in flow rate, temperature and mobile phase composition did not cause any significant changes in the results. RSD for precision was $<2 \%$, confirming that this method is sufficiently precise.

\section{CONCLUSION}

The developed method has a significant advantage over other methods of analysis because it is capable of simultaneous determination of multiple active components present in combination dosage form, resulting in a faster, more cost-effective analysis. The time required for sample analysis is a few hours. The method has been validated extensively as per $\mathrm{ICH}$ guidelines, and it is suitable for use in pharmaceutical firms and laboratories.

\section{DECLARATIONS}

\section{Acknowledgement}

The authors thank Wallace Pharmaceuticals Private Limited, Goa, India for providing resources for formulation and subsequent analysis.

\section{Conflict of interest}

The authors confirm that no conflict of interest is associated with this study.

\section{Contributions of authors}

We confirm that this work was done by the author(s) named in this manuscript, and all liabilities pertaining to claims relating to the content of this article will be borne by the authors. SVS conceived the study and participated in the design as well as analysis and interpretation of data and in the drafting of the manuscript. SLT was involved in the acquisition of data, its analysis and interpretation, and drafting of the manuscript. MTB was involved in critically revising the manuscript for important intellectual content. All authors read and approved the final manuscript.

\section{Open Access}

This is an Open Access article that uses a funding model which does not charge readers or their institutions for access and distributed under the terms of the Creative Commons Attribution License (http://creativecommons.org/licenses/by/ 4.0) and the Budapest Open Access Initiative (http://www.budapestopenaccessinitiative.org/rea d), which permit unrestricted use, distribution, and reproduction in any medium, provided the original work is properly credited.

\section{REFERENCES}

1. Sawant $R$, Joshi R, Lanke $P$, Bhangale L. Simultaneous Estimation and Validation of Paracetamol, Phenylephrine Hydrochloride and Chlorpheniramine Maleate in Tablets by Spectrophotometric Method. Asian Journal of Pharmaceutical Research and Health Care 2011; 3(2): 23-28.

2. 2. Marín A, García E, García A, Barbas C. Validation of a HPLC quantification of acetaminophen, phenylephrine, and chlorpheniramine in pharmaceutical formulations: capsules and sachets. Journal of Pharm Biomedical Analysis 2002; 29(4): 701-714.

3. 3. Maithani, M, Raturi R, Gautam V, Dharmendra K, Chaudhary AK, Gaurav A, and Ranjit S. Development and validation of a RP-HPLC method for the determination of chlorpheniramine maleate and phenylephrine in pharmaceutical dosage form. Pharmacie Globale International Journal of Comprehensive Pharmacy 2010; 1 (05): 1-4. 
4. Nikam AD, Pawar SS, Gandhi SV. Simultaneous spectrophotometric estimation of Aceclofenac and Paracetamol. Asian Journal of Chemistry 2007; 19(7): 5075-5080.

5. Senyuva H, Ozden T. Simultaneous High-Performance Liquid Chromatographic method for determination of Paracetamol, Phenylephrine HCL and Chlorpheniramine Maleate in Pharmaceutical Dosage Forms. Journal of Chromatographic Science 2002; 40(2): 97-100.

6. Rajurkar SS. Simultaneous determination of Chlorpheniramine Maleate, Paracetamol, And Pseudoephedrine Hydrochloride in Pharmaceutical Preparations by HPLC. International Journal of Life Science and Pharma Research 2011; 1(1): 94-100.

7. Redasani VK, Gorale AP, Badhan RA, Jain PS, Surana SJ. Simultaneous determination of chlorpheniramine maleate, phenylephrine hydrochloride, paracetamol, and caffeine in pharmaceutical preparation by RP-HPLC. Chemical Industry \& Chemical Engineering Quarterly 2013; 19 (1): 57-65.

8. Patel M, Parashar AK, Tiwari M, Majumdar AJ, Nema RK. Simultaneous estimation of Phenylephrine Hydrochloride and Benzyl Alcohol by First Derivative Spectrophotometric Method. Current Research in Pharmaceutical Sciences 2012; 04: 215-218.

9. Yadav OM, Jain HK. RP-HPLC Method Development and Validation for simultaneous estimation of Phenylephrine Hydrochloride and Ebastine in Tablet Dosage Form. International Journal of Pharmacy and Pharmaceutical Sciences 2014; 6(8): 466-470.

10. Jaiswal KR. Analytical method development and validation of RP-HPLC for simultaneously estimation of chlorpheniramine maleate, dextromethorphan hydrobromide, Phenylephrine Hydrochloride in Cough Syrup. International Journal of Advances in Science Engineering and Technology 2016; 4(1): 35-39.

11. Sheikh S, Asghar S, Patni S. A Validated, Specific Stability Indicating Reverse Phase Liquid Chromatographic Method for simultaneous estimation of Phenylephrine HCL, Betamethasone Valerate and Lignocaine in Pharmaceutical Ointment. International Journal of Scientific and Research Publications. 2012; 2(12): 1-8.

12. Sethuraman S, Radhakrishan K, Amol ST. Method Development and validation of Caffeine in tablet dosage form by using UV Spectroscopy. International Journal of Novel Trends in Pharmaceutical Sciences, 2013; 3(4): 82-86.

13. Tsvetkova B, Kostova B, Pencheva I, Zlatkov A, Rachev $D$, Peikova P. Validated LC Method for Simultaneous Analysis of Paracetamol and Caffeine in model tablet formulation. International Journal of Pharmacy and Pharmaceutical Sciences. 2012; 4(4): 680-684.

14. Altun ML. HPLC Method for the analysis of Paracetamol, Caffeine and Dipyrone, Turkish Journal of Chemistry 2002; 26: 521-528.

15. Laxminarayan $V$, Austin $A$. Determination of Acetaminophen and Caffeine using RP-LC technique. Journal of Research in Pharmaceutical Research 2016; 3(4): 5-10.

16. ICH, Q2 (R1). Validation of analytical procedures: Text and Methodology International Conference on Harmonization, Geneva, Switzerland, 2005. 